\title{
Glucan Biosynthesis Protein G Is a Suitable Reference Gene in Escherichia coli K-12
}

\author{
Sean S. J. Heng, ${ }^{1}$ Oliver Y. W. Chan, ${ }^{1}$ Bryan M. H. Keng, ${ }^{1}$ and Maurice H. T. Ling ${ }^{2}$ \\ ${ }^{1}$ Raffles Institution, One Raffles Institution Lane, Singapore 575954 \\ ${ }^{2}$ Department of Zoology, The University of Melbourne, Genetics Lane, Parkville, Victoria 3010, Australia
}

Correspondence should be addressed to Maurice H. T. Ling, mauriceling@acm.org

Received 29 August 2011; Accepted 13 October 2011

Academic Editors: H. I. Atabay and H.-P. Horz

Copyright () 2011 Sean S. J. Heng et al. This is an open access article distributed under the Creative Commons Attribution License, which permits unrestricted use, distribution, and reproduction in any medium, provided the original work is properly cited.

\begin{abstract}
The expressions of reference genes used in gene expression studies are assumed to be stable under most circumstances. However, a number of studies had demonstrated that such genes were found to vary under experimental conditions. In addition, genes that are stably expressed in an organ may not be stably expressed in other organs or other organisms, suggesting the need to identify reference genes for each organ and organism. This study aims at identifying stably expressed genes in Escherichia coli. Microarray datasets from E. coli substrain MG1655 and 1 dataset from W3110 were analysed. Coefficient of variance (COV) of was calculated and $10 \%$ of the lowest COV from 4631 genes common in the 3 MG1655 sets were analysed using NormFinder. Glucan biosynthesis protein $\mathrm{G}(m d o G)$, which is involved in cell wall synthesis, displayed the lowest weighted COV and weighted NormFinder Stability Index for the MG1655 datasets, while also showing to be the most stable in the dataset for substrain W3110, suggesting that $m d o G$ is a suitable reference gene for E. coli K-12. Gene ontology over-representation analysis on the 39 genes suggested an overrepresentation of cell division, carbohydrate metabolism, and protein synthesis which supports the short generation time of $E$. coli.
\end{abstract}

\section{Introduction}

Gene expression analysis is examining the variations in gene expression as a result of changes in environmental conditions by measuring DNA expression levels over time. Quantitative real-time polymerase chain reaction (qRT-PCR) is a commonly used technique to quantify gene expressions [1]. However, several parameters need to be controlled in this process in order to obtain accurate and reliable results. These include variations in the amounts of starting material between samples, RNA extraction efficiency, RNA integrity/quality, efficiency of cDNA synthesis, and differences in the overall transcriptional activity of the cells analyzed. Of which, only the differences in transcriptional activity is of interest. A possible method for accounting other effects is relative normalization, which is the correction of the raw expression values with a reference gene. The reference gene acts as an invariant endogenous control which implies that reference genes should be stably expressed under a wide variety of conditions [2].

However, several studies had suggested that it is not easy to find universal reference genes [3-5]. This corroborates several studies demonstrating that several genes originally considered invariable in terms of expression may vary under different experimental conditions [6-8]. For an accurate comparison of DNA expression in different samples, it is necessary to use verified reference genes, such as GAPDH (glyceraldehyde-3-phosphate dehydrogenase) [9] or UBQ (ubiquinone) [9], for normalisation or determine new ones for each experimental system with varying external stimuli $[3,10]$. However, some studies had also demonstrated that the expression of GAPDH [11] and UBQ [12] is varying in some conditions. Other studies had also identified references genes, such as recA (recombinase A), proC (pyrroline-5-carboxylase reductase) and gyrA (DNA gyrase) in Pectobacterium atrosepticum [8], and map (methionine 
aminopeptidase), rpoC (RNA polymerase, beta prime subunit), and alaS (alanyl-tRNA synthetase) in Acidithiobacillus ferrooxidans [13]. This suggests that established reference genes for a particular organism may not be suitable for other organisms.

Escherichia coli, a Gram-negative bacterium commonly found in the gastrointestinal tract, was selected as it has a genome of approximately 4,000 genes. In addition, the genetic material in its plasmids is easily manipulated. Furthermore, E. coli is easily cultured and is a commonly studied prokaryotic model $[14,15]$. As it is easily cultured in the laboratory environment and is of low pathogenicity [16-18].

Candidate reference genes, which are commonly believed to be invariant, can be identified using algorithms such as geNorm [19], NormFinder [20], and BestKeeper [21]. These methods require a wide range of accessible gene expression data, normally obtained through DNA profiling such as quantitative PCR. However, microarrays, which usually contain thousands of probes, present a good source of data for identifying reference genes [22]. A recent study had successfully identified MARK3 as a suitable reference gene in mouse liver using microarray analysis [23].

Currently, there are numerous studies being conducted to validate known reference genes and possibly identify new ones $[3,8,9,13,24]$. In this study, we identify and evaluate a set of invariant genes in E. coli K-12 substrains MG1655 and W3110. Our results suggest that glucan biosynthesis protein $G(m d o G)$ is a suitable reference gene for both MG1655 and W3110 strains of E. coli.

\section{Materials and Methods}

2.1. Microarray Data. Four datasets were obtained from publicly available microarray databases, Gene Expression Omnibus, National Centre for Biotechnology Information, of which 3 were from E. coli $\mathrm{K}-12$ substrain MG1655 and 1 from substrain W3110. Briefly, the studies conducted with the datasets are as follows: GDS680: MG1655 grown in either aerobic or anaerobic conditions, deleted for transcriptional regulators in oxygen response, and used to validate a computational model of transcriptional and metabolic networks. GDS1099: aerobically grown MG1655 cells in several media with varied carbon sources including glucose, glycerol, succinate, L-alanine, acetate, and L-proline. GDS1494: analysis of derivatives of strain 1655: wild type, fur mutant, and wild type with added $\mathrm{FeSO}_{4}$, induced to overexpress $R y h B$, a noncoding RNA regulated by the fur repressor protein. GDS1827: W3110 cells grown aerobically and exposed to low, neutral, or high $\mathrm{pH}$ to study acid and base response.

2.2. Finding Invariant Genes. The coefficient of variation (COV) of every gene was calculated as the quotient of standard deviation and arithmetic mean. From 4631 genes, the top $10 \%$ with the lowest COV from each dataset were listed. The intersection between the 3 MG1655 data sets (GDS680, GDS1099, and GDS1494) was identified and analysed using NormFinder version 0.953 [20] to rank the stability of these genes. A weighted stability index for each gene was then calculated from the NormFinder's stability index, and an average of the NormFinder stability indexes multiplied by number of samples was taken.

2.3. Gene Ontology Overrepresentation Analysis. The list of genes from the intersection of the top $10 \%$ with the lowest COV from the 3 MG1655 data sets were analysed for gene ontology overrepresentation using the Gene ontology gene annotation file for E. coli dated July 8, 2011. Chi-square test was carried out to identify the overrepresented gene ontology terms in the list of genes using the overall $P$ value of 0.01 , corrected for multiple testing using Holm-Bonferroni method [25].

2.4. Comparing NormFinder and COV. Spearman's correlation was used to determine the correlation between stability index generated by NormFinder and COV values using the equation $r=1-\left[6 \sum d_{i}^{2} /\left(n\left(n^{2}-1\right)\right)\right]$, where $r$ is the Spearman's correlation, $d$ is the difference in the rank of two parameters, and $n$ is the sample size. The $t$-statistic was calculated by equation $t=r \sqrt{(n-2) /\left(1-r^{2}\right)}$, which was used to test for the null hypothesis of no correlation with $(n-2)$ degrees of freedom.

\section{Results and Discussion}

A threshold of less than $10 \%$ COV was used to select stably expressed genes across the three datasets GDS 680, 1099, and 1494 (MG1655). A total of 39 genes of consistent low variance were found (Table 1) with the weighted COV values ranging from 0.099 to 0.138 . Glucan biosynthesis protein $\mathrm{G}(m \mathrm{~m} o G)$ was found to be most stable with both the lowest weighted COV value and weighted NormFinder Stability Index for MG1655. In GDS 1827 (W3110), mdoG was the most stable in the dataset, with a COV of 0.088 and NormFinder Stability Index of 0.078. The highest COV in GDS 1827 is 0.791 for hslV (peptidase component of the HslUV protease). Our results suggest that $m d o G$ may be a suitable reference gene across both E. coli strains W3110 and MG1655. This may imply that $m d o G$ may be suitable for use as reference genes in other strains of E. coli K-12.

Gene ontology overrepresentation is a commonly used mechanistic analysis method to provide biological insights into a list of genes [26-28]. The analysis of the 39 genes with consistently low variance for gene ontology overrepresentation showed that 3 primary functions were found to be overrepresented (Table 2). They were cell division, carbohydrate metabolic process, and protein synthesis. As E. coli is generally accepted as a rapidly dividing prokaryote [29], it is plausible to expect genes responsible for cell division to be constantly expressed. As the cells grow, new cellular structures, such as cell wall and other enzymes, need to be synthesized. Hence, it is plausible to expect protein synthesis to be stable throughout the cell cycle. The role of glutathione $[30,31]$ and tetrapyrrole [32] had been implicated in protein synthesis while diaminopimelate had been shown to have a role in the maintenance of cell wall [33]. At the same time, cell division involves the replication and segregation of 
TABLE 1: Weighted mean COV and NormFinder stability index of 39 invariant genes across 3 datasets (MG1655).

\begin{tabular}{|c|c|c|c|}
\hline Gene symbol & Gene name & Weighted COV values & $\begin{array}{l}\text { Weighted NormFinder } \\
\text { Stability Index }\end{array}$ \\
\hline$m d o G$ & Glucan biosynthesis protein $\mathrm{G}$ & 0.099 & 0.082 \\
\hline dapA & Dihydrodipicolinate synthase & 0.106 & 0.090 \\
\hline $\operatorname{crp}$ & DNA-binding transcriptional dual regulator & 0.106 & 0.102 \\
\hline$h s l V$ & Peptidase component of the HslUV protease & 0.111 & 0.105 \\
\hline $\operatorname{mrdB}$ & Cell wall shape-determining protein & 0.101 & 0.114 \\
\hline$f u c U$ & L-Fucose mutarotase & 0.107 & 0.117 \\
\hline yjgP & LPS transport $(l p t F)$ & 0.105 & 0.117 \\
\hline yigC & 3-Octaprenyl-4-hydroxybenzoate decarboxylase & 0.126 & 0.117 \\
\hline sun & $\begin{array}{l}\text { 16S rRNA m(5)C967 methyltransferase, } \\
\text { S-adenosyl-L-methionine-dependent }\end{array}$ & 0.130 & 0.119 \\
\hline gor & Glutathione oxidoreductase & 0.117 & 0.126 \\
\hline$h f l B$ & ATP-dependent metalloprotease & 0.127 & 0.130 \\
\hline yqiB & Predicted dehydrogenase & 0.125 & 0.134 \\
\hline murG & N-Acetylglucosaminyl transferase & 0.124 & 0.134 \\
\hline$y r b G$ & Predicted calcium/sodium:proton antiporter & 0.122 & 0.134 \\
\hline yejK & Nucleotide associated protein & 0.120 & 0.141 \\
\hline$y f g A$ & Cytoskeletal protein required for $M r e B$ assembly & 0.118 & 0.142 \\
\hline$h f l X$ & Putative GTPase $H f l X$ & 0.105 & 0.142 \\
\hline spot & $\begin{array}{l}\text { Bifunctional ( } p \text { )ppGpp synthetase II/guanosine- } \\
3^{\prime}, 5^{\prime} \text {-bis pyrophosphate } 3^{\prime} \text {-pyrophosphohydrolase }\end{array}$ & 0.117 & 0.143 \\
\hline holC & DNA polymerase III, chi subunit & 0.134 & 0.144 \\
\hline$x e r D$ & Site-specific tyrosine recombinase & 0.114 & 0.146 \\
\hline tolB & Periplasmic protein & 0.115 & 0.146 \\
\hline yhes & $\begin{array}{l}\text { Fused predicted transporter subunits of ABC } \\
\text { superfamily: ATP-binding components }\end{array}$ & 0.110 & 0.146 \\
\hline$n t p A$ & Dihydroneopterin triphosphate pyrophosphatase & 0.118 & 0.147 \\
\hline$y a b B$ & Conserved protein, $M r a Z$ family & 0.115 & 0.148 \\
\hline lolA & Chaperone for lipoproteins & 0.117 & 0.153 \\
\hline$y g g D$ & Predicted DNA-binding transcriptional regulator & 0.116 & 0.153 \\
\hline pnp & Polynucleotide phosphorylase/polyadenylase & 0.110 & 0.155 \\
\hline$y r b B$ & $\begin{array}{l}\text { ABC transporter maintaining OM lipid asymmetry, } \\
\text { cytoplasmic STAS component }\end{array}$ & 0.123 & 0.156 \\
\hline$r n c$ & RNase III & 0.117 & 0.157 \\
\hline xerC & Site-specific tyrosine recombinase & 0.138 & 0.160 \\
\hline$r f a F$ & ADP-heptose:LPS heptosyltransferase II & 0.120 & 0.161 \\
\hline yigP & Conserved protein, SCP2 family & 0.122 & 0.164 \\
\hline gyrB & DNA gyrase, subunit B & 0.126 & 0.164 \\
\hline nagC & $\begin{array}{l}\text { DNA-binding transcriptional dual regulator, repressor } \\
\text { of } \mathrm{N} \text {-acetylglucosamine }\end{array}$ & 0.132 & 0.165 \\
\hline$n r d R$ & Conserved protein & 0.118 & 0.168 \\
\hline hemD & Uroporphyrinogen III synthase & 0.108 & 0.169 \\
\hline pheT & Phenylalanine tRNA synthetase, beta subunit & 0.124 & 0.171 \\
\hline frr & Ribosome recycling factor & 0.129 & 0.173 \\
\hline$c l s$ & Cardiolipin synthase 1 & 0.129 & 0.181 \\
\hline
\end{tabular}

genetic material [34]. Carbohydrate is both a primary source of energy for E. coli [35] as well as the primary component of bacterial cell wall [36]. The gene $m d o G$ has been shown to be involved in the formation of the $\beta-1,6$ glucose linkage
[37] and in the periplasmic release of newly synthesized osmoregulated periplasmic glucans $[38,39]$, which is needed for bacterial cell wall. Thus, it is plausible that the expression of $m d o G$ is needed during binary fission. As E. coli divides 
TABLE 2: Gene ontology overrepresentation of the 39 invariant genes.

\begin{tabular}{|c|c|c|c|}
\hline Primary function & GOID & Gene ontology terms & $P$ value \\
\hline \multirow{10}{*}{ Cell division } & GO:0071139 & Cell cycle & $5.51 E-61$ \\
\hline & GO:0006276 & Plasmid recombination & $6.01 E-31$ \\
\hline & GO:0016051 & Cell division & $2.90 E-16$ \\
\hline & GO:0006432 & Plasmid maintenance & $2.90 E-16$ \\
\hline & GO:0042594 & Response to starvation & $3.39 E-11$ \\
\hline & GO:0007049 & Chromosome segregation & $6.61 E-09$ \\
\hline & GO:0017038 & Resolution of recombinant intermediates & $1.21 E-08$ \\
\hline & GO:0006004 & Guanosine tetraphosphate metabolic process & $1.21 E-08$ \\
\hline & GO:0042953 & Lysogeny & $4.20 E-07$ \\
\hline & GO:0051301 & Diaminopimelate biosynthetic process & $3.50 E-06$ \\
\hline \multirow{3}{*}{ Carbohydrate metabolism } & GO:0030259 & Carbohydrate biosynthetic process & $2.34 E-31$ \\
\hline & GO:0006749 & Lipid glycosylation & $2.34 E-31$ \\
\hline & GO:0007059 & Fucose metabolic process & $8.08 E-13$ \\
\hline \multirow{8}{*}{ Protein synthesis } & GO:0030069 & Phenylalanyl-tRNA aminoacylation & $2.34 E-31$ \\
\hline & GO:0016075 & RNA catabolic process & $2.34 E-31$ \\
\hline & GO:0015969 & Lipoprotein transport & $2.90 E-16$ \\
\hline & GO:0019277 & Phenylalanyl-tRNA aminoacylation & $2.90 E-16$ \\
\hline & GO:0042150 & Protein import & $3.39 E-11$ \\
\hline & GO:0006396 & RNA processing & $2.48 E-09$ \\
\hline & GO:0033014 & Tetrapyrrole biosynthetic process & $1.21 E-08$ \\
\hline & GO:0019877 & Glutathione metabolic process & $4.20 E-07$ \\
\hline
\end{tabular}

rapidly, constant synthesis of cell wall is needed. Therefore, it is likely that mdoG is constantly needed, which may be a reason to its constant expression in E. coli. Hence, both gene ontology overrepresentation and the function of the most stably expressed gene, mdoG, support the short generation time of E. coli.

Our results showed that none of the 7 housekeeping genes consistently appeared in the lowest $10 \%$ COV subset of each dataset (Table 3), while GAPDH [9], gyrA [8], and alas [13] were found to be in the lowest $10 \%$ COV subset, in one dataset each. Our results illustrated that $\operatorname{rec} A$ [8] has the highest weighted COV of 0.5378 and gyrA [8] has the lowest weighted COV of 0.1607 , which is higher than that of $m d o G$ (COV of 0.099). This suggests that commonly used housekeeping genes such as GAPDH [9] and recA [8] are not suitable for the expression profiling of E. coli. Hence, our results support our earlier hypothesis that common housekeeping genes found to be stable in one organism cannot be assumed to be stable in all organisms. This suggests the need to identify suitable reference genes for each organism of interest.

The advantage of COV is its capability to analyse as large number of samples as required [23] as the number of calculations increases proportionally to the sample size, resulting in linear complexity. NormFinder uses residual analysis between sample subgroup variation and the overall variation of the expression dataset to evaluate the variation contributed by each gene in the entire dataset [20]. Thus, the computational complexity of NormFinder increases exponentially as the number of samples increases; hence, it
TABLE 3: Seven housekeeping genes and their mean COV values across 4 datasets.

\begin{tabular}{lcc}
\hline Gene symbol & Gene name & $\begin{array}{c}\text { Weighted } \\
\text { COV values }\end{array}$ \\
\hline recA & Recombinase A & 0.537752244 \\
proC & Pyrroline-5-carboxylate reductase & 0.257211257 \\
gyrA & DNA gyrase & 0.16070208 \\
map & Methionine aminopeptidase & 0.282917613 \\
rpoC & RNA polymerase, beta prime subunit & 0.273422333 \\
alaS & Alanyl-tRNA synthetase & 0.160829965 \\
GAPDH & Glyceraldehyde-3-phosphate & 0.230513521 \\
& dehydrogenase & \\
\hline
\end{tabular}

is only able to work with a small number of genes within reasonable time and computational resources. Therefore, we used Spearman's rank correlation coefficient to determine the correlation of stability index by NormFinder and COV values which showed that the sum of $d^{2}$ was 5664 and the $P$ value was 0.006748 . Since the $P$ value was less than 0.01 , the null hypothesis is rejected, indicating that there is correlation between the stability index from NormFinder and COV values but the strength of this correlation is difficult to establish as the significance in $P$ value did not indicate the correlation strength. However, our results do not suggest that $\mathrm{COV}$ is a suitable replacement for NormFinder. As NormFinder [20] takes account of the overall variability in the entire dataset, it is likely to be statistically stronger than 
COV which is a normalized standard deviation. Given the advantageous ability of COV to process large amounts of data such as those derived from microarrays, it is plausible that $\mathrm{COV}$ can be used as a weaker filter for a broad category of genes with low expression variation, followed by stronger statistical analysis by NormFinder [20] to identify suitable reference genes.

\section{Acknowledgment}

The authors wish to thank H. P. Too (Biochemistry, National University of Singapore) for his discussion and input into this study.

\section{References}

[1] O. Fedrigo, L. R. Warner, A. D. Pfefferle, C. C. Babbitt, P. CruzGordillo, and G. A. Wray, "A pipeline to determine RT-QPCR control genes for evolutionary studies: application to primate gene expression across multiple tissues," PLoS ONE, vol. 5, no. 9, Article ID e12545, pp. 1-7, 2010.

[2] N. Agabian, L. Thomashow, M. Milhausen, and K. Stuart, "Structural analysis of variant and invariant genes in trypanosomes," American Journal of Tropical Medicine and Hygiene, vol. 29, supplement, no. 5, pp. 1043-1049, 1980.

[3] T. Czechowski, M. Stitt, T. Altmann, M. K. Udvardi, and W. R. Scheible, "Genome-wide identification and testing of superior reference genes for transcript normalization in arabidopsis," Plant Physiology, vol. 139, no. 1, pp. 5-17, 2005.

[4] M. Jain, A. Nijhawan, A. K. Tyagi, and J. P. Khurana, "Validation of housekeeping genes as internal control for studying gene expression in rice by quantitative real-time PCR," Biochemical and Biophysical Research Communications, vol. 345, no. 2, pp. 646-651, 2006.

[5] N. Nicot, J. F. Hausman, L. Hoffmann, and D. Evers, "Housekeeping gene selection for real-time RT-PCR normalization in potato during biotic and abiotic stress," Journal of Experimental Botany, vol. 56, no. 421, pp. 2907-2914, 2005.

[6] U. E. M. Gibson, C. A. Heid, and P. M. Williams, "A novel method for real time quantitative RT-PCR," Genome Research, vol. 6, no. 10, pp. 995-1001, 1996.

[7] S. R. Stürzenbaum and P. Kille, "Control genes in quantitative molecular biological techniques: the variability of invariance," Comparative Biochemistry and Physiology. B, vol. 130, no. 3, pp. 281-289, 2001.

[8] G. W. Takle, I. K. Toth, and M. B. Brurberg, "Evaluation of reference genes for real-time RT-PCR expression studies in the plant pathogen Pectobacterium atrosepticum," BMC Plant Biology, vol. 7, article 50, 2007.

[9] N. C. Noriega, S. G. Kohama, and H. F. Urbanski, " $\kappa$ Microarray analysis of relative gene expression stability for selection of internal reference genes in the rhesus macaque brain," BMC Molecular Biology, vol. 11, article 47, 2010.

[10] T. Remans, K. Smeets, K. Opdenakker, D. Mathijsen, J. Vangronsveld, and A. Cuypers, "Normalisation of real-time RTPCR gene expression measurements in Arabidopsis thaliana exposed to increased metal concentrations," Planta, vol. 227, no. 6, pp. 1343-1349, 2008.

[11] E. M. Glare, M. Divjak, M. J. Bailey, and E. H. Walters, “ $\beta$ actin and GAPDH housekeeping gene expression in asthmatic airways is variable and not suitable for normalising mRNA levels," Thorax, vol. 57, no. 9, pp. 765-770, 2002.
[12] L. Gutierrez, M. Mauriat, S. Guénin et al., "The lack of a systematic validation of reference genes: a serious pitfall undervalued in reverse transcription-polymerase chain reaction (RT-PCR) analysis in plants," Plant Biotechnology Journal, vol. 6, no. 6, pp. 609-618, 2008.

[13] P. A. Nieto, P. C. Covarrubias, E. Jedlicki, D. S. Holmes, and R. Quatrini, "Selection and evaluation of reference genes for improved interrogation of microbial transcriptomes: case study with the extremophile Acidithiobacillus ferrooxidans," BMC Molecular Biology, vol. 10, article 63, 2009.

[14] J. E. Barrick, D. S. Yu, S. H. Yoon et al., "Genome evolution and adaptation in a long-term experiment with Escherichia coli," Nature, vol. 461, no. 7268, pp. 1243-1247, 2009.

[15] T. F. Cooper, D. E. Rozen, and R. E. Lenski, "Parallel changes in gene expression after 20,000 generations of evolution in Escherichia coli," Proceedings of the National Academy of Sciences of the United States of America, vol. 100, no. 3, pp. 1072-1077, 2003.

[16] B. Janke, U. Dobrindt, J. Hacker, and G. Blum-Oehler, "A subtractive hybridisation analysis of genomic differences between the uropathogenic E. coli strain 536 and the E. coli K12 strain MG1655," FEMS Microbiology Letters, vol. 199, no. 1, pp. 61-66, 2001.

[17] N. A. Khan and G. J. Goldsworthy, "Novel model to study virulence determinants of Escherichia coli K1," Infection and Immunity, vol. 75, no. 12, pp. 5735-5739, 2007.

[18] P. Kuhnert, J. Hacker, I. Mühldorfer, A. P. Burnens, J. Nicolet, and J. Frey, "Detection system for Escherichia coli-specific virulence genes: absence of virulence determinants in $\mathrm{B}$ and $\mathrm{C}$ strains," Applied and Environmental Microbiology, vol. 63, no. 2, pp. 703-709, 1997.

[19] J. Vandesompele, K. de Preter, F. Pattyn et al., "Accurate normalization of real-time quantitative RT-PCR data by geometric averaging of multiple internal control genes," Genome biology, vol. 3, no. 7, pp. 0034.1-0034.11, 2002.

[20] C. L. Andersen, J. L. Jensen, and T. F. Ørntoft, "Normalization of real-time quantitative reverse transcription-PCR data: a model-based variance estimation approach to identify genes suited for normalization, applied to bladder and colon cancer data sets," Cancer Research, vol. 64, no. 15, pp. 5245-5250, 2004.

[21] M. Kubista, R. Sindelka, A. Tichopad, A. Bergkvist, D. Lindh, and A. Forooran, "The prime technique. Real-time PCR data analysis," GIT Laboratory Journal, vol. 9, no. 10, pp. 33-35, 2007.

[22] E. Wurmbach, T. Yuen, and S. C. Sealfon, "Focused microarray analysis," Methods, vol. 31, no. 4, pp. 306-316, 2003.

[23] C. Y. Chia, C. W. X. Lim, W. T. Leong, and M. H. T. Ling, "High expression stability of microtubule affinity regulating kinase 3 (MARK3) makes it a reliable reference gene," IUBMB Life, vol. 62, no. 3, pp. 200-203, 2010.

[24] L. P. Boava, M. L. Laia, T. R. Jacob et al., "Selection of endogenous genes for gene expression studies in Eucalyptus under biotic (Puccinia psidii) and abiotic (acibenzolar-Smethyl) stresses using RT-qPCR," BMC Research Notes, vol. 3, article no. 43, 2010.

[25] S. Holm, "A simple sequentially rejective multiple test procedure," Scandinavian Journal of Statistics, vol. 6, no. 2, pp. 6570, 1979.

[26] P. Khatri and S. Drăghici, "Ontological analysis of gene expression data: current tools, limitations, and open problems," Bioinformatics, vol. 21, no. 18, pp. 3587-3595, 2005.

[27] A. M. Lewin and I. C. Grieve, "Grouping Gene Ontology terms to improve the assessment of gene set enrichment in 
microarray data," BMC Bioinformatics, vol. 7, article 426, 2006.

[28] S. Zhang, J. Cao, Y. M. Kong, and R. H. Scheuermann, "GOBayes: gene ontology-based overrepresentation analysis using a Bayesian approach," Bioinformatics, vol. 26, no. 7, Article ID btq059, pp. 905-911, 2010.

[29] T. Durfee, A. M. Hansen, H. Zhi, F. R. Blattner, and J. J. Ding, "Transcription profiling of the stringent response in Escherichia coli," Journal of Bacteriology, vol. 190, no. 3, pp. 1084-1096, 2008.

[30] R. S. Dhindsa, "Glutathione Status and Protein Synthesis during Drought and Subsequent Rehydration in Tortula ruralis," Plant Physiology, vol. 83, no. 4, pp. 816-819, 1987.

[31] S. Yoshida, A. Kaibara, K. Yamasaki, N. Ishibashi, T. Noake, and T. Kakegawa, "Effect of glutamine supplementation on protein metabolism and glutathione in tumor-bearing rats," Journal of Parenteral and Enteral Nutrition, vol. 19, no. 6, pp. 492-497, 1995.

[32] R. Tanaka and A. Tanaka, "Tetrapyrrole biosynthesis in higher plants," Annual Review of Plant Biology, vol. 58, pp. 321-346, 2007.

[33] A. Wehrmann, B. Phillipp, H. Sahm, and L. Eggeling, "Different modes of diaminopimelate synthesis and their role in cell wall integrity: a study with Corynebacterium glutamicum," Journal of Bacteriology, vol. 180, no. 12, pp. 3159-3165, 1998.

[34] O. Huisman, R. D’Ari, and S. Gottesman, "Cell-division control in Escherichia coli: specific induction of the SOS function SfiA protein is sufficient to block septation," Proceedings of the National Academy of Sciences of the United States of America, vol. 81, no. 14 I, pp. 4490-4494, 1984.

[35] R. J. Wang, H. G. Morse, and M. L. Morse, "Carbohydrate accumulation and metabolism in Escherichia coli: characteristics of the reversions of ctr mutations," The Journal of Bacteriology, vol. 104, no. 3, pp. 1318-1324, 1970.

[36] J. van Heijenoort, "Formation of the glycan chains in the synthesis of bacterial peptidoglycan," Glycobiology, vol. 11, no. 3, pp. 25-36, 2001.

[37] I. Loubens, L. Debarbieux, A. Bohin, J. M. Lacroix, and J. P. Bohin, "Homology between a genetic locus (mdoA) involved in the osmoregulated biosynthesis of periplasmic glucans in Escherichia coli and a genetic locus (hrpM) controlling pathogenicity of Pseudomonas syringae," Molecular Microbiology, vol. 10, no. 2, pp. 329-340, 1993.

[38] J. P. Bohin, "Osmoregulated periplasmic glucans in Proteobacteria," FEMS Microbiology Letters, vol. 186, no. 1, pp. 11-19, 2000.

[39] F. Page, S. Altabe, N. Hugouvieux-Cotte-Pattat, J. M. Lacroix, J. Robert-Baudouy, and J. P. Bohin, "Osmoregulated periplasmic glucan synthesis is required for Erwinia chrysanthemi pathogenicity," Journal of Bacteriology, vol. 183, no. 10, pp. 3134-3141, 2001. 

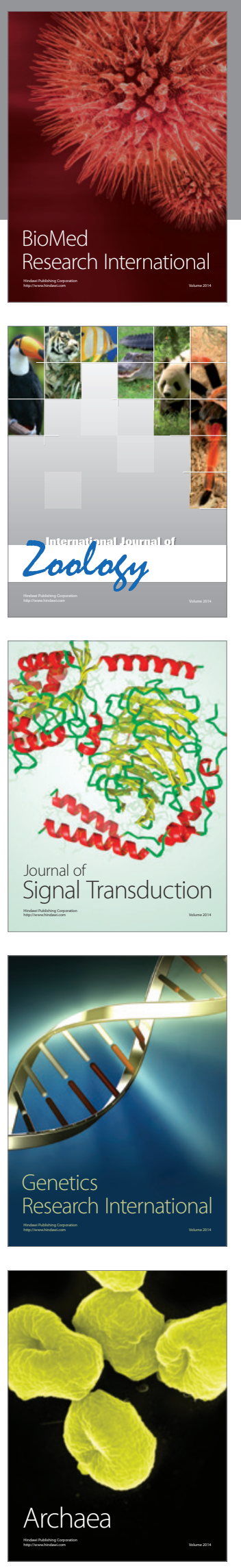
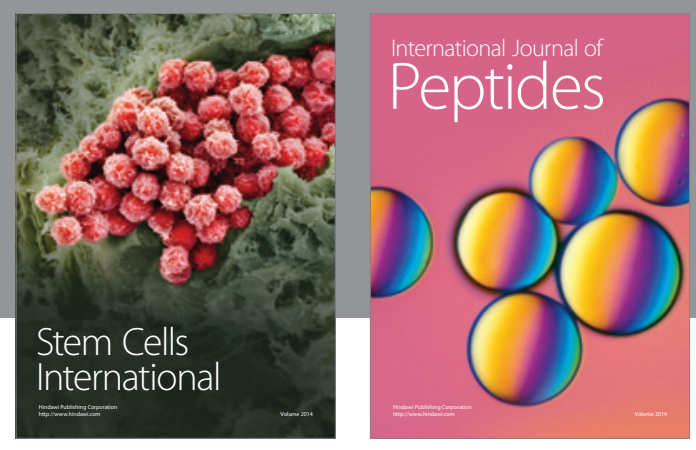

Submit your manuscripts at

http://www.hindawi.com
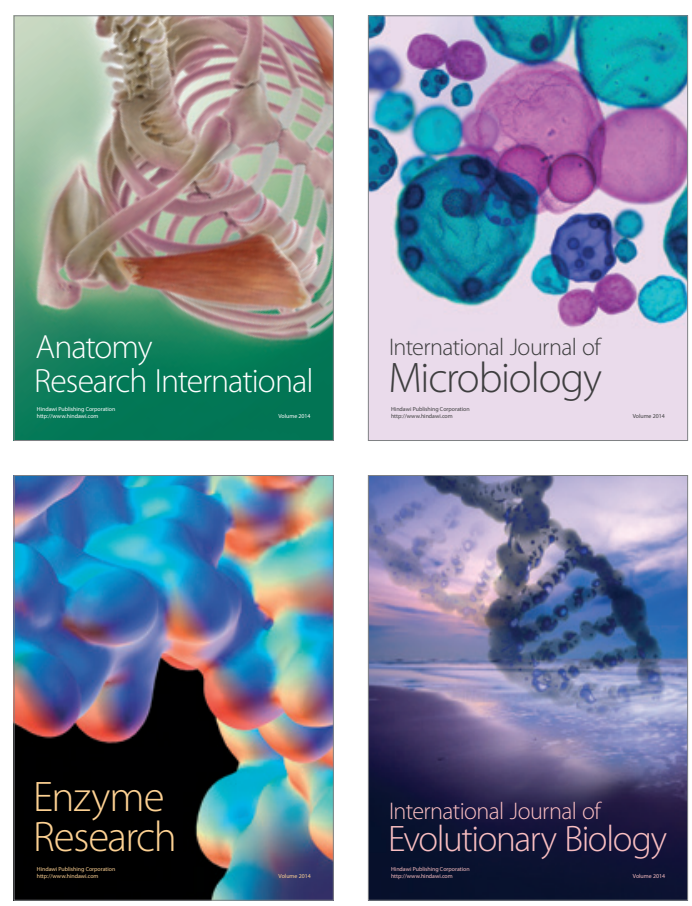
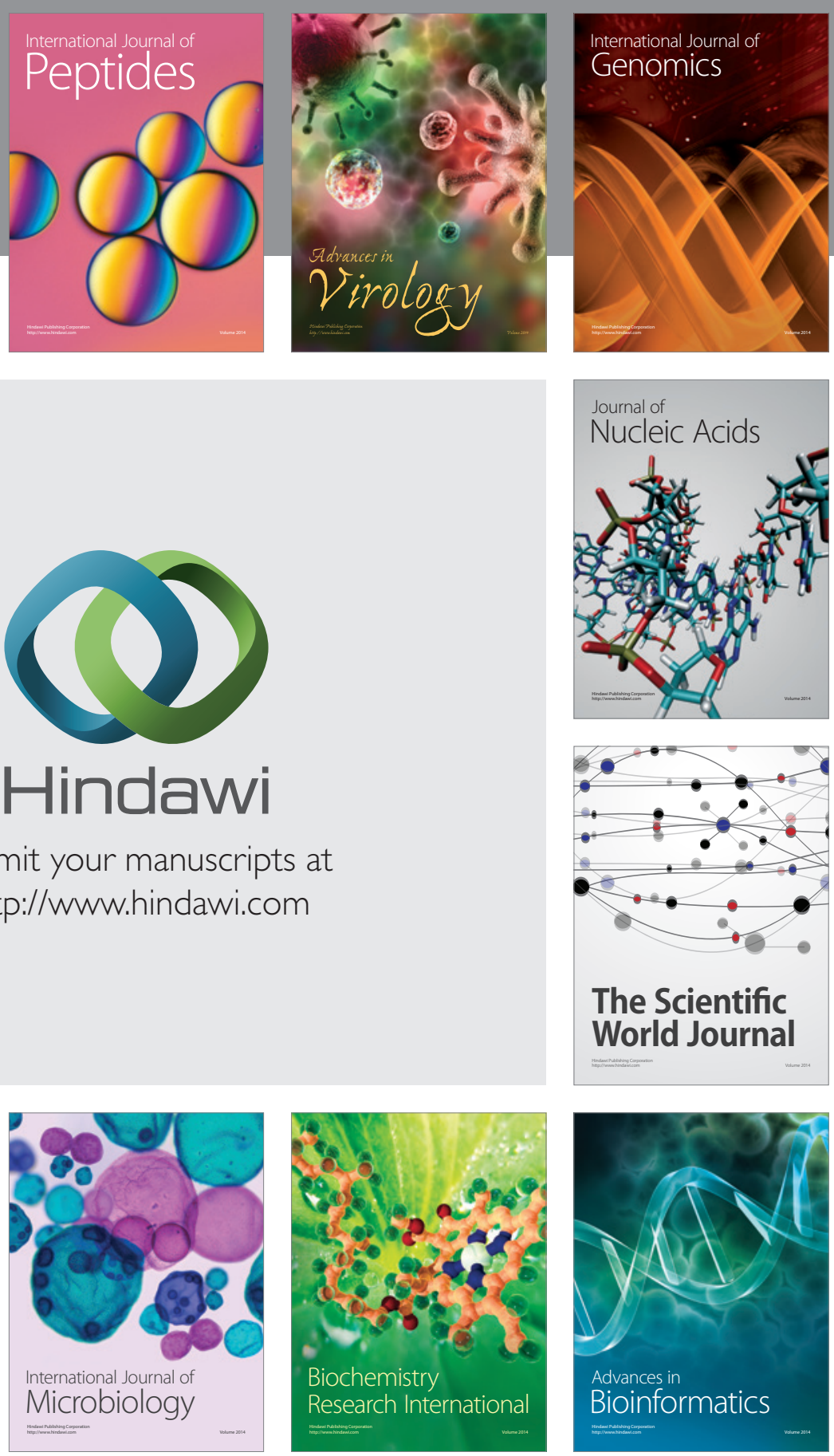

The Scientific World Journal
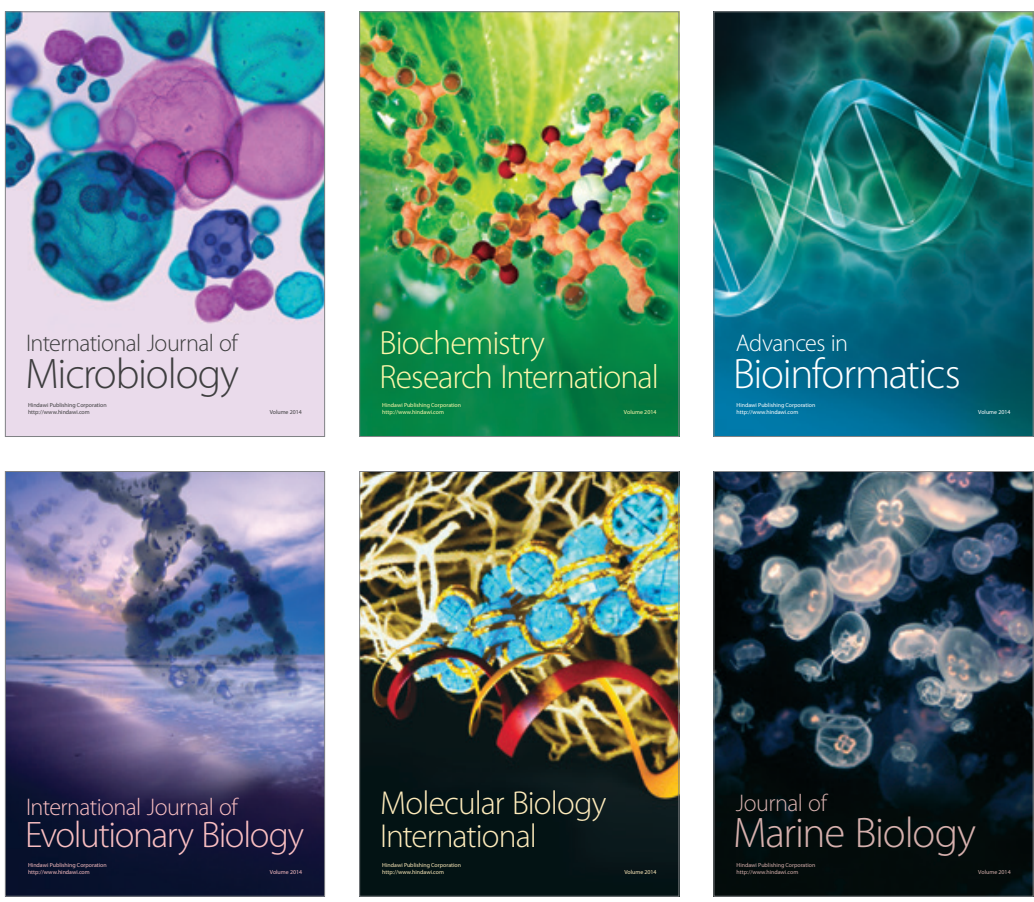